\title{
Neuroimaging in anxiety disorders
}

\author{
Kirsten Engel · Borwin Bandelow · Oliver Gruber • \\ Dirk Wedekind
}

Received: 6 March 2008/Accepted: 1 June 2008/Published online: 21 June 2008

(C) The Author(s) 2008

\begin{abstract}
Neuroimaging studies have gained increasing importance in validating neurobiological network hypotheses for anxiety disorders. Functional imaging procedures and radioligand binding studies in healthy subjects and in patients with anxiety disorders provide growing evidence of the existence of a complex anxiety network, including limbic, brainstem, temporal, and prefrontal cortical regions. Obviously, "normal anxiety" does not equal "pathological anxiety" although many phenomena are evident in healthy subjects, however to a lower extent. Differential effects of distinct brain regions and lateralization phenomena in different anxiety disorders are mentioned. An overview of neuroimaging investigations in anxiety disorders is given after a brief summary of results from healthy volunteers. Concluding implications for future research are made by the authors.
\end{abstract}

Keywords Anxiety disorders - Panic disorder .

Phobia $\cdot$ Neuroimaging $\cdot$ fMRI $\cdot$ Prefrontal cortex .

Limbic system $\cdot$ Insular cortex

\section{Introduction}

There has been an enormous increase in studies on anxiety disorders implying neuroimaging procedures. Improved techniques for structural imaging such as computed

Dedicated to the special issue on ANXIETY.

K. Engel · B. Bandelow · O. Gruber · D. Wedekind $(\square)$

Department of Psychiatry and Psychotherapy,

Anxiety Research Unit, University of Goettingen,

von-Siebold-Strasse 5, 37075 Goettingen, Germany

e-mail: dwedeki1@gwdg.de tomography studies and structural MRI have brought diverse results and hypotheses on the neuroanatomy of anxiety up from the 1980s. However, the findings of these studies hardly correspond.

In 1980, research and classificatory criteria for anxiety disorders have emerged in DSM-III. These made standardized investigations methodologically possible and with the improvement of a neurophysiological and neurobiological understanding of anxiety disorders the idea of a neural anxiety network consolidated. With distinct neocortical, limbic, and brainstem structures involved in the generation and processing of anxiety symptoms and disorders, the need for confirmation has become the incentive of neuroimaging studies. Considering the enormous methodological progress, imaging procedures gain an increasing importance in research on the pathogenesis of anxiety disorders. There is growing evidence that brain areas involved in the stress response, including the prefrontal cortex, hippocampus and amygdala, play a role in the symptoms of anxiety. In the past few years, brain imaging studies have been dedicated to the progress of understanding of the neural circuitry of anxiety disorders (Bremner 2004).

However, it has became obvious that some areas involved in anxiety processing like the amygdalae, distinct brainstem nuclei or the periaquaductal gray (PAG) are hard to detect with sufficient resolution because of their sizes and anatomical locations (closeness to structures of different density like bone or body liquids). Nevertheless, with increasing quality of methods, results become more and more precise and now allow for a consolidation of neuronal network hypotheses in anxiety disorders. Radioligand studies and investigations on regional cerebral blood flow [using e.g. positron emission tomography (PET) and single photon emission computed tomography (SPECT)] 
are to assess regional blood flow differences or altered binding of ligands in distinct regions compared to control conditions such as healthy subjects or pre/post treatment differences. The past years have brought about a number of studies using high resolution functional magnetic resonance imaging, which provide valid statements for different stimulation paradigms in patients with anxiety disorders and in stimulated healthy subjects. Such stimulatory conditions can be either psychological or pharmacological and correlate with regional changes of activity.

Investigations incorporated into this review have been chosen on the base of a med-line research with the keywords neuroimaging and either panic disorder, agoraphobia, social anxiety disorder or generalized anxiety disorder. Due to their large amount, research articles on specific phobia have been selected on the base of their impact on disorder specific neuroanatomical models, as judged by the authors. Out of the plenty of animal imaging data and findings in healthy human subjects only few exemplary articles have been chosen to facilitate the introduction to anxiety disorder specific models.

In line with both classificatory systems DSM-IV (American Psychiatric Association 1998) and ICD-10 (World Health Organisation 1993) and in order to make this article as concise as possible, no research articles on post-traumatic stress disorder (PTSD) and obsessiveconvulsive disorder (OCD) have been implemented.

Due to the relative unspecificity and the limitations of structural imaging data, their presentation is kept short in this article.

Following a brief introduction about selected findings from animal studies and healthy probands, an overview on neuroimaging research work is given and implications for future perspectives are made. Brief introduction to the clinical syndrome of the respective disorders are given in the beginning of each chapter and preliminary conclusions from the research data are tried to be made.

\section{Implications from animal research}

In anxiety paradigms, it has become evident that the medial prefrontal cortex plays an essential role in the inhibition of conditioned fear following extinction. These neuronal pathways inhibit central amygdala nucleus output and inputs from the insula and basolateral amygdala (Quirk et al. 2003). Amat et al. (2005) showed that the ventral medial prefrontal cortex in rats detects whether a stressor is under control of the organism. If this is the case, dorsal raphe activity is blocked.

Milad and Quirk (2002) showed that destruction of the ventral medial prefrontal cortex in animals impairs recall of extinction. This structure might store long-term extinction memory and inhibits fear in subsequent encounters with fear stimuli. Thus, previously learned coping strategies with external and internal stressors would be processed from this region.

\section{Healthy subjects}

Functional magnetic resonance imaging (fMRI)

Using fMRI during a fear conditioning paradigm in healthy subjects, amygdalae activation was increased (LaBar et al. 1998). Another investigation showed amygdalae activation on presentation of non-conditioned, fear-related or negatively affect-loaded stimuli, too (Grodd et al. 1995). Gottfried and Dolan (2004) could demonstrate that in humans that orbitofrontal cortex and amygdalae activity were preferably enhanced during extinction learning of previously conditioned aversive stimuli. Etkin et al. (2006) found that activity in the amygdala and dorsomedial and dorsolateral prefrontal cortices reflects the amount of emotional conflict, when a coping-strategy seems not to be directly available. The amygdala activation appears to be personality dependent and correlates with neuroticism (Haas et al. 2007). Final resolution of the emotional conflict goes in line with anterior cingulate cortex (ACC) activity and correlates with reduction of amygdalae activity (top-down inhibition). Herry et al. (2007) suggested that amygdala function increases with the unpredictability of a stimulus or situation. Paulus et al. (2004), however, implied that activation of the ACC and medial prefrontal cortex was significantly higher in high trait-anxiety subjects and was correlated with trait but not state anxiety. Possibly, this feature characterizes subjects who scan their environment more thoroughly for anxiety inducing stimuli but also for coping factors. According to (Phelps et al. 2004), ventromedial prefrontal cortex activation (anterior cingulate) seems to be primarily linked to expression of fear learning during delayed tests of extinction.

Jensen et al. (2003) proposed that the ventral striatum, which is associated with the reward system, is activated in anticipation of adverse stimuli. Yet, Yaguez et al. (2005) showed that actual and anticipated aversive stimuli (pain) elicited similar cortical responses, including activation of ACC, insula, primary and secondary somatosensory cortices. This is in line with Simmons et al. (2004), who observed insula, dorsolateral prefrontal cortex, and parahippocampal gyrus activation during anticipation of aversive affective images. Interestingly, Critchley et al. (2002) demonstrated that conditioning-related neural activity is modulated by both awareness and representations of bodily states and autonomic arousal. Absent 
peripheral autonomic arousal, in patients with autonomic denervation was associated with decreased conditioning related activity in insula and amygdala.

In a meta-analysis of PET and fMRI studies on emotion in healthy volunteers, (Phan et al. 2002) proclaimed certain brain regions to be associated to distinct emotions and executive functions, e.g. the amygdalae for fear and the medial prefrontal cortex for emotional processing. In a recent fMRI study by Dannlowski et al. (2007), however, it could be demonstrated that amygdala hyperreactivity correlated with negative automatic emotion processing (in depressive patients). Activity in the basolateral amygdala elicited by unconscious emotional processing was predicted by individual differences in trait anxiety in healthy subjects using fMRI. This phenomenon was not detected in the dorsal amygdala that is modulated by conscious emotional processing (Etkin et al. 2004). High trait anxiety healthy subjects display higher amygdala and insula activation during processing of emotional stimuli compared to a normative group (Stein et al. 2007). State anxiety, however, is associated with higher ventral amygdala responses in healthy subjects (Somerville et al. 2004). Application of the selective serotonin re-uptake inhibitor escitalopram over 21 days could significantly reduce amygdala activation during an emotional task compared to placebo in healthy probands (Arce et al. 2008). This may well fit into a theoretical framework of negative emotional processing as suggested by LeDoux (1996) stressing an unconscious, "fast" way of automatic amygdala mediated responses to potentially threatening stimuli.

Nevertheless, in a classical conditioning paradigm using PET, healthy subjects reacted to stimulation with an increase of cerebral blood flow (CBF) in the thalamus, hypothalamus, periaqueductal grey (PAG) and cingulate but not in the amygdalae (Fredrikson et al. 1995; Furmark et al. 1997; Morris et al. 1996).

\section{Chemically induced anxiety}

The panicogen cholecystokinine-tetrapeptide (CCK-4) is a neurokinine binding to central nervous and peripheral sites. Intravenous application causes a dose-dependent brief and impetuous anxiety state with psychic and somatic anxiety symptoms. Infusion of CCK-4 in healthy subjects increased activity in the cerebellar vermis, both temporal lobes and amygdalae, thalamus and anterior cingulate as measured with fMRI. Anticipatory anxiety activated temporal lobes and insulae, right prefrontal cortex, thalamus, cingulate and the temporo-parieto-occipital gyrus (Schunck et al. 2006). Eser et al. (2007) reported an intense ACC, medial frontal cortex, and temporal lobe activation in healthy subjects by CCK-4 compared to placebo in healthy subjects. Anticipatory anxiety phenomena were less pronounced and related to the dorsal ACC. Effects were independent of the occurrence of a panic attack, subjective levels of anxiety correlated with amygdala activation.

\section{Panic disorder}

Panic disorder is a condition characterized by repeated limited episodes of intense somatic and psychic anxiety symptoms. Symptoms such as dyspnea, palpitations, tachycardia, sweating, tremor, nausea and depersonalization, fear of losing control or dying emerge in specific situations or "out of the blue" and increase within a few minutes. Such panic attacks usually result in an intense and ongoing fear of the next expected attack (phobophobia). This may lead to avoidance behaviour with patients refraining situations in which they may become helplessly panicky. Panic disorder very often is associated with agoraphobia, a fear of certain situations (such as elevators, wide places, crows of people, theatres) from which fleeing is expected to be difficult.

Structural imaging

\section{Computed tomography $(C T)$}

In a number of CT studies, some distinct structural alterations in panic disorder patients were detected in low to medium sample sizes. Most results were rather unspecific [demonstrating enlarged ventricles in the prefrontal cortex (Wurthmann et al. 1997)], slight atrophy, diminished brain/ ventricles ratio or lacunary infarctions, and could not be replicated [e.g. normal brain/ventricles ratio (Uhde et al. 1987)]. Lepola et al. (1990) found structural abnormalities in 6 of 30 panic patients. In conclusion, CT cannot be regarded as an appropriate tool for investigating the neuroanatomy of panic anxiety due to its low resolution.

\section{Magnetic resonance imaging (MRI)}

Structural MRI-studies revealed hardly more specific and conclusive results compared to $\mathrm{CT}$ investigations. In panic patients structural alterations were found in the temporal lobes, predominantly on the right side (Fontaine et al. 1990; Ontiveros et al. 1989). One investigation reported diminished volumina of both temporal lobes, despite unaltered hippocampi (Vythilingam et al. 2000).

Uchida et al. (2003) found a reduced left temporal lobe volume and a trend to reduced right temporal lobe, left and right amygdala and the left hippocampal area volume.

One study indicates reduced grey matter density in the left hippocampus of panic patients (Massana et al. 2003a).

Another morphometric investigation on panic disorder patients revealed higher grey matter volume in the 
mesencephalon of the rostral pons and to a slightly lower extent in the ventral hippocampus combined with less prefrontal cortex volume (Protopopescu et al. 2006). A voxel-based morphometric study found bilaterally diminished putamen volumina (Yoo et al. 2005). Volumetric magnetic resonance imaging (MRI) studies performed by Massana et al. (2003b) found patients to have smaller leftsided and right-sided amygdala volumes than controls. No differences were detected in either hippocampi or temporal lobes.

Functional imaging

\section{Regional cerebral blood flow (CBF) under basal conditions}

Three studies investigated basal CBF in patients suffering from panic disorder. In one $\left[{ }^{18}\right.$ FDG]-PET investigation, a lowered metabolic rate in the left inferior parietal lobe was found compared to controls (Nordahl et al. 1990). Posterior temporal lobe, inferior parietal lobe and cerebellar cortex CBF was decreased bilaterally (Malizia et al. 1998), whereas on study showed increased CBF in the left hippocampus (Bisaga et al. 1998).

Sakai et al. (2005) accessed cerebral glucose metabolism in patients with panic disorder using F-fluorodeoxyglucose positron emission tomography with voxel-based analysis to compare regional brain glucose utilization and showed that patients exhibited significantly higher levels of glucose uptake in the bilateral amygdala, hippocampus, and thalamus, and in the midbrain, caudal pons, medulla, and cerebellum than controls. After successful treatment both cognitive behavioural treatment and antidepressant treatment resulted in comparable decreases of previous activations (Prasko et al. 2004).

On trial implying Tc99m-HM-PAO-SPECT in panic patients detected a bilateral frontal decrease and a right pronounced medial and superior frontal increase of regional blood-flow. CBF asymmetry with a shift to the right side correlated with disorder severity as measured with the Bandelow Panic and Agoraphobia Scale (P\&A) (Eren et al. 2003). Comparable results were found by Lee et al. (2006) with patients showing decreased $\mathrm{CBF}$ in the right upper temporal lobe. $\mathrm{CBF}$ in this region was negatively correlated with panic disorder severity.

\section{GABA-/benzodiazepine receptors}

$\left[{ }^{11} \mathrm{C}\right]$ Flumazenil binding to benzodiazepine receptors was generally diminished in patients compared to controls, especially in the right insular region and in the right orbitofrontal cortex (Malizia et al. 1998). These results could be replicated lately by Cameron et al. (2007) who showed diminished binding in the insular cortices bilaterally correlating with disorder severity and comorbid depression.

Several studies used $\left[{ }^{123}\right.$ I]Iomazenil-SPECT to investigate benzodiazepine receptor binding.

Kuikka et al. (1995) found increased iomazenil signalling in the temporal cortex and in the right laterofrontal gyrus in drug-free panic disorder patients compared to healthy controls. Brandt et al. (1998) compared drug-free patients and controls as well and found increased iomazenil binding in the right orbitofrontal cortex. The left hippocampal area revealed less benzodiazepine-receptor binding (Bremner et al. 2000).

One investigation compared panic disorder patients with patients suffering from epilepsy showing lower iomazeniluptake in the frontal, occipital and temporal cortex (Schlegel et al. 1994).

Comparing panic patients with comorbid major depression to patients suffering from dysthymia, who were all on antidepressant medication, a lower iomazenil binding in both lower lateral temporal lobes, in the left medial inferior temporal lobe and in both orbitofrontal lobes could be demonstrated for panic disorder (Kaschka et al. 1995).

Using ${ }^{1} \mathrm{H}$-magnetic resonance spectroscopy, a reduced GABA concentration in the occipital cortex could be measured (Goddard et al. 2001).

In a consequent trial, the authors could find a lowering of occipital GABA reduction after benzodiazepine administration (Goddard et al. 2004).

Another study revealed significantly decreased GABA concentration in the anterior cingulate (ACC) and in the basal ganglia in panic patients compared to controls (Ham et al. 2007). Lactate and choline concentrations in the ACC in patients were higher.

\section{Serotonin binding studies}

In one PET study, a reduced serotonin-5- $\mathrm{HT}_{1 \mathrm{~A}}$-receptor binding in the cingulate and raphe nuclei could be found (Neumeister et al. 2004).

Maron et al. (2004) found that patients with current PD showed a significant decrease in 5-HT transporter binding in the midbrain, temporal lobes and thalamus compared to controls by SPECT. Regional binding significantly and negatively correlated with the severity of panic symptoms. The binding in patients in remission, however, was comparable to findings in the control group.

Creatine and phosphocreatine are metabolites involved in energy dependent brain systems. In the frontal lobes of panic patients a higher phosphocreatine concentration was found on the left side (Shioiri et al. 1996).

${ }^{1} \mathrm{H}$-magnetic resonance spectroscopy revealed a reduced creatine/phosphocreatine concentration in the medial prefrontal cortex in one study (Massana et al. 2002). 
Anxiety provocation and challenge tests

\section{Provocation of presentation of visual anxiety-related stimuli}

After presentation of potentially threatening words, panic patients displayed activation in the left posterior cingulum and the left medial frontal cortex (Maddock et al. 2003) in the f-MRI.

On presentation of words with negative emotional valence patients reacted with an activation of the right amygdala and right hippocampus (van den Heuvel et al. 2005).

Stimulation with anxiety related pictures went in line with increased activity in the inferior frontal cortex, the hippocampus, the anterior and posterior cingulate and the orbitofrontal cortex (Bystritsky et al. 2001).

On presentation of anxious faces panic patients displayed, compared to controls, a lower activation of the anterior cingulate cortex and the amygdalae (Pillay et al. 2006). This was discussed in a way that patients had a reduced reaction to acute emotional cues because of a chronic hyperarousal. Happy faces went in line with a bilateral activation of the anterior cingulate cortices but not with amygdala alterations (Pillay et al. 2007).

Domschke et al. (2006) reported correlations between distinct genetic polymorphisms of the serotonergic system and a lower activation of the right prefrontal cortex and increased activity of both amygdalae after presentation of faces with emotional expressions.

\section{Panic provocation by sodium lactate infusions}

Panic provocation with sodium lactate or other panicogens can be associated with artefacts by induced vasoconstriction (Ball and Shekhar 1997). Also, respiratory changes caused by acute (state anxiety) or continuous (trait anxiety) fear and anxiety may influence results of functional MR imaging (Giardino et al. 2007).

In one PET study by (Reiman et al. 1989) a decreased left to right ratio of parahippocampal CBF was seen in panic disorder patients. However, these results could not be replicated by (Drevets et al. 1992) and turned out to be artefacts by extracerebral signals, namely patients' gritting of teeth.

In a trial using 99mTc-HM-PAO-SPECT seven sodiumlactate sensitive panic disorder patients were compared to five healthy controls (De Cristofaro et al. 1993). In the patient group, increased $\mathrm{CBF}$ in the right orbitofrontal cortex was detected. Additionally, CBF was higher in the left occipital cortex and lower bilaterally in the hippocampus and the amygdalae. Using $\left[{ }^{133} \mathrm{Xe}\right]-\mathrm{SPECT}$, patients who did not panic after sodium lactate as well as in controls, hemispheric CBF after the infusion was increased (Stewart et al. 1988). This was not the case in patients who had panicked, but maybe because of induced hyperventilation decreasing CBF. Yet, patients who experienced a panic attack had an increase of CBF in the occipital lobe.

Sodium-lactate infusion causes an increased lactate concentration in the brain. The increase is more pronounced in panic disorder patients than in controls. This was demonstrated using proton echo planar spectroscopic imaging (PEPSI). Particular regions not displaying such an increase could not be identified (Dager et al. 1999).

Panic patients had a larger and prolonged sodium lactate increase in the insular cortices (Dager et al. 1994, 1997) as detected by magnetic resonance spectroscopy (MRS).

\section{Panic provokation by yohimbine}

During yohimbine-induced anxiety, cerebral vasoconstriction was observed. Patients showed an attenuated activation of the frontal cortex compared to controls using HM-PAO-SPECT (Woods et al. 1988).

\section{Panic provocation by cholecystokinine (CCK)}

After CCK induced anxiety healthy volunteers displayed an increase of extracerebral blood flow in the region of the superficial temporal artery (Benkelfat et al. 1995) as measured by PET. The authors hypothesized that regional blood flow changes that were measured in previous study might be caused by muscular activity.

There is one study which investigated anticipatory anxiety before infusion of the CCK-B agonist pentagastrin. After the challenger there was no more hypothalamic CBF increase but a larger activity of the right amygdala (Boshuisen et al. 2002).

\section{Panic provocation by doxapram}

In response to the respiratory stimulant doxapram, which can induce panic attacks, panic disorder patients tended to decrease prefrontal activity more than controls, and increased cingulate gyrus and amygdala activity more than controls (Garakani et al. 2007).

\section{Spontaneous panic attacks}

Pfleiderer et al. (2007) recently reported on a female patient with panic disorder experiencing an (accidental) spontaneous panic attack under an auditory habituation paradigm in fMRI at $3 \mathrm{~T}$. This is the first report on spontaneous panic under such conditions. The panic attack was associated with a significantly increased activity in the right amygdala. 
Panic disorder: concluding remarks

Neurocircuitry models of panic disorder have hypothesized that the panic attack itself stems from loci in the brainstem including the ascending reticular system and respiratory and cardiovascular control centres. Panic might be controlled as well as to originate from a dysfunction of frontal and temporal limbic circuitries. According to Gorman et al. (2000) a neuronal "fear network" centered in the amygdala is controlled by medial prefrontal areas via the hippocampus. Amygdala projections to brainstem nuclei might account for many of the somatic anxiety symptoms during a panic attack. Entero- and exteroceptive awareness might be increased by a greater reagibility of the insular cortex. In subsequent phenomena such as expectancies ("fear of fear") and avoidance prefrontal cortical areas obviously appear to be predominantly involved. Side asymmetries with decreased activity of inhibitory, prefrontal structures and increased activity in limbic areas on the dominant hemisphere are evident. However, many studies cannot be considered conclusive because of several methodological limitations, and challenge paradigms are not easy to perform in this patient group in the scanner. Despite of this, the amount of investigations in panic disorder exceeds the number of those in the other anxiety disorders by far. Volpe et al. (2004) suggested longitudinal and multi-modal studies involving larger patient samples, possibly integrated with population-based and genetic studies, would provide more insight into pathophysiological mechanisms of panic disorder. Nevertheless, a dysfunctional serotonergic system might be of importance since several parameters associated with serotonergic function are altered in panic disorder and treatment with serotonergic drugs can reduce activity of distinct regions of the "fear network" in the direction of controls.

\section{Generalized anxiety disorder (GAD)}

Generalized anxiety disorder is a disorder characterized by continuous symptom of anxiety and vegetative hyperarousal associated with extreme and exaggerated sorrows. Sorrows might deal with thoughts that relatives or family members could be harmed or have an accident when they are out of the patient's control. Sorrows may also be about financial or occupational issues. Patients are aware that their fear of anything adverse happening is not realistic and that their sorrows are exaggerated (meta-sorrows).

\section{Structural imaging}

In comparatively small samples of GAD and panic disorder patients some subjects revealed unspecific CCT alterations such as enlarger ventricles (Lauer and Krieg 1992). Compared to children with panic attacks, children with GAD had a higher grey to white matter ratio in the upper temporal lobe. This was more pronounced on the right side, whereas there were no differences in the thalamus and the frontal cortex (De Bellis et al. 2002).

\section{Functional imaging}

Only over the recent years, results from imaging studies allow for differentiated statements about regional CBF alterations (Nutt 2001). Under basal conditions no consistent changes were observed. Under psychological stress, however, a reduction of CBF was found (Nutt 2001). Using xenon-inhalation-technique a negative correlation between CBF and anxiety could be shown. Nevertheless, under resting conditions no differences to controls emerged (Mathews and Wilson 1987).

Positron emission tomography investigations revealed increased metabolism in the occipital, temporal, frontal, and cerebellar region and a lower CBF in the basal ganglia of patients with GAD after presentation of an anxietyinducing task (Wu et al. 1991). Under comparable conditions an amplification of activity emerged in the basal ganglia (Buchsbaum et al. 1987). Mathew et al. (2004) recently described that GAD patients had a $16.5 \%$ higher $\mathrm{N}$-acetylaspartate/creatine ratio, a suggested marker of neuronal viability, in the right dorsolateral prefrontal cortex compared with healthy controls. A total of 13 of 15 matched patient-comparison subject pairs displayed such a difference. In a recent meta-analysis (Etkin and Wager 2007) greater amygdala and also insula activity was reported for GAD in negative emotional processing compared to healthy controls. Patients with GAD had a better treatment response to fluoxetine or cognitive behavioural therapy when pre-treatment amygdala activity was strong (McClure et al. 2007). Treatment response to venlafaxine, however, was predicted by lower amygdala and higher ACC reactivity to fearful faces in the fMRI (Whalen et al. 2008). With regard to prefrontal activity Monk et al. (2006) found greater fMRI BOLD responses in the right ventrolateral prefrontal cortex to emotionally adverse stimuli compared to healthy controls. In adolescents with GAD disorder severity correlated positively with right amygdala activation on presentation of angry faces. This finding was negatively associated to right ventrolateral prefrontal cortex activity, a phenomenon that was evident to an even higher degree in healthy controls (Monk et al. 2008).

There is still a relative paucity of GAD studies. Amygdala and insula function seem to be of importance in this disorder and a dysfunction of the ventrolateral prefrontal cortex could be of relevance. 


\section{Social anxiety disorder (SAD)}

Social anxiety disorder is characterized by extreme and exagerated fears of being scrutinized by others and to be a target of criticism leading to awkward situations. Social situations (e.g. public speaking, performances, interactions with authority persons or members of the opposite sex) in which the subjects expects his appearance and behaviour to be evaluated by others (mostly unfamiliar persons) are avoided or tolerated with intense anxiety symptoms which are again expected to be detected by others. Panic attacks may occur in the course of this disorder. A performance type, an interaction type, and a generalized type can be distinguished.

\section{Structural imaging}

The study by Potts et al. (1996) found an overall volume reduction of the putamen of patients compared to controls by MRI.

\section{Functional imaging}

\section{Phobic stimulation paradigms}

Birbaumer et al. (1998) showed bilateral amygdalae activation in SAD patients under phobic stimulation using fMRI. Stein et al. (2002) however, investigated a signal increase in amygdalae, uncus, and gyrus parahippocampalis in patients in the fMRI on presentation of faces expressing negative affectivity, exclusively. This could be confirmed by Evans et al. (2007) and Phan et al. (2006) in generalized SAD patients who were shown aversive faces displaying higher amygdalae activation. The extent of activation correlated with SAD severity and was reversible after antidepressant treatment (Norbury et al. 2007).

Lorberbaum et al. (2004) scanned generalized social phobics anticipating public speaking by fMRI. They showed greater subcortical, limbic, and lateral paralimbic activity (pons, striatum, amygdala, uncus, anterior parahippocampus, insula, temporal lobe), regions important in automatic emotional processing. Cortical activity (dorsal ACC, prefrontal cortex) (important for cognitive processing) was reduced. Interestingly, Campbell et al. (2007) could demonstrate that amygdala and prefrontal cortex responses to emotional faces occurred later in generalized social phobics than in healthy controls.

Kilts et al. (2006) demonstrated in PET scans of SAD subjects that mental imagery resulted in left postcentral gyrus, lenticulate right inferior frontal gyri and medial temporal gyri activity. Mental arithmetic tasks activated medial and left dorsolateral prefrontal cortex, cerebellum, thalamus, insula and ventral striatum. Both conditions went in line with right amygdala and hippocampus activation.
In paired conditioning paradigms-simultaneous presentation of a conditioned (neutral facial expression) and an unconditioned stimulus (neutral or aversive odour) patients displayed a significant increase in amydalae and hippocampus activity compared to control subjects (Schneider et al. 1999). fMRI scans by Straube et al. (2005) demonstrated increased activity in the extra-striate visual cortex on presentation of faces regardless of expression. Angry faces, however, elicited greater insula activation. Amygdala, parahippocampal gyrus and extra-striate visual cortex were more strongly activated in an implicit subtask (type of picture, not expression) (Straube et al. 2004b). Yoon et al. (2007) also reported higher bilateral amygdala activation in generalized social phobics compared to healthy controls when faces with high emotional intensity were presented.

Kagan described a childhood phenomenon "behavioural inhibition" that is characterized by avoidance of novel stimuli, objects and situations. Adults who had been diagnosed as "inhibited" in the second year of life showed a more pronounced amygdala activation in the fMRI on presentation of unfamiliar faces (Schwartz et al. 2003).

One SPECT-study found no differences with regard to CBF between SAD and healthy subjects (Stein and Leslie 1996).

After provocation by phobic stimuli PET showed a signal increase in the right prefrontal cortex and in the left parietal cortex. This phenomenon did not show under phobic anticipation in controls (Malizia et al. 1997).

Another PET study was performed to measure SAD patient's $\mathrm{CBF}$ in a state of anticipatory anxiety before public speaking. An increased $\mathrm{CBF}$ in the right dorsolateral prefrontal cortex, the left inferior temporal cortex and the left hippocampus-amydala complex was detected, additionally a decrease of CBF in the left temporal pole and bilaterally in the cerebellum.

During and after stimulation SAD patients showed an overall increase of subcortical CBF compared to healthy controls who had an elevation of cortical CBF (Tillfors et al. 2002). Similar elevations of CBF in generalized SAD in the thalamus, midbrain, the lateral, prefrontal and medial cingulum, and the sensomotoric, anterotemporal cortex were stated by investigations by Reiman (1997). Under stimulatory conditions a decrease of activity in the visualand the mediofrontal cortex could be demonstrated (van Ameringen et al. 1998).

\section{Metabolic changes, treatment effects, and serotonergic function}

Davidson et al. (1993) and Tupler et al. (1997) could distinguish different distributions of amino-acids by magnetic resonance tomography in SAD patients for instance in the 
thalamus and the caudate nucleus. Relating to these investigations a lower metabolic rate in the basal ganglia of patients with SAD was proposed. Magnetic resonance spectroscopy revealed an increased uptake of fluoxetine in distinct areas of the brain in SAD patients who had improved clinically significantly under this treatment before (Miner et al. 1995). Successful pharmacotherapy reduced activity in the left temporal lobe, left frontal cortex and left cingulum as accessed by HMPAO-SPECT (van der Linden et al. 2000). In a PET study after phobic stimulation, SAD patients who had clinically improved under citalopram treatment had decreased CBF in both amygdalae, hippocampus, and in the paraamygdaloid, rhinal, and parahippocampal cortex compared to measurements before pharmacological treatment. Changes correlated obviously with clinical improvement and differed significantly to untreated controls (Furmark et al. 2002). More evidence for a serotonergic dysfunction was given by Lanzenberger et al. (2007) who found a significantly lower 5-HT1A receptor binding in several limbic and paralimbic areas of SAD patients, most significantly in the amygdala followed by the anterior cingulate cortex, insula, and dorsal raphe nuclei.

Recent theories propose a dysfunction of the dopaminergic system in SAD. Using the cocaine analogue $\left[{ }^{123} \mathrm{I}\right]-$ Beta-CIT a reduced density of dopamine reuptake sites in SAD patients was demonstrated (Tiihonen et al. 1997). An IBZM-SPECT study found a lower $\mathrm{D}_{2}$-binding capacity in SAD patients (Schneier et al. 2000).

In an open-label treatment trial (Kelsey et al. 2000) with nefazodone correlates of social anxiety under stimulation before treatment were obvious in the cortex bilaterally, the medial temporal lobe, caudate nucleus, frontal lobe, and in the lateral orbitofrontal cortex. Medial frontal lobe $\mathrm{CBF}$ correlated with experienced anxiety to a high degree. After treatment, $\mathrm{CBF}$ alterations with phobic stimulation still could be seen in the right medial orbitofrontal cortex and in the anterior cingulum. After successful treatment with citalopram or a neurokinin-1 antagonist a reduced response of the rhinal cortex, amygdala and the hippocampal area during a public speaking task was detected in patients with social phobia (Furmark et al. 2005). Another interesting study by the same authors (Furmark et al. 2004) showed that carriers of one or two copies of the short allele of the serotonin transporter gene had, besides elevated levels of trait- and state anxiety, a higher exitability of the right amygdala to anxiety provocation compared to carriers of two long allele copies.

\section{Social anxiety disorder: concluding remarks}

Following a neuroanatomical model by (Li et al. 2001) it has been proposed, that in SAD there was a dysfunction of a cortico-striato-thalamic network. This could partially stated by Sareen et al. (2007) showing a striatal dysfunction associated with generalized social phobia. According to Li, the parietal cortex plays an important role in the evaluation of body position and the "social space". Via connections between thalamus and basal ganglia there is an increased transmission to the frontal cortex. A more negative evaluation of social situations would result and consequently their avoidance. (Veit et al. 2002) presume a hyperactive frontolimbic system that tends to misinterpret potentially anxiety-inducing cues. Amir et al. (2005) stressed the importance of the ACC in SAD in processing negative emotional information. However, compared to patients with posttraumatic stress disorder (PTSD), according to the meta-analysis of Etkin and Wager (2007), SAD patients did not show alterations of the ACC, although amygdala and insula activity was higher than in healthy controls.

Social anxiety disorder seems to be characterized by a hyperreactive (right) prefrontal cortex in combination with a striatal dysfunction and increased hippocampus and amygdalae activity with a lateralization to the left. Insula activity goes in line with somatic anxiety, whereas the ACC is important in anticipation of adverse stimuli. Serotonergic drugs were consistently able to diminish these phenomena according to clinical improvement.

\section{Specific phobia}

Specific phobia is a disorder characterized by an intense and exaggerated fear of specific and isolated situations and objects. Animal phobias are the most frequent subtype (spiders, snakes, mice). Extreme anxiety symptoms might emerged in the presence of the feared object, even thinking about it may cause symptoms. Places where a confrontation is expected are usually avoided. This may lead to restrictions in daily life, when e.g. a bedroom cannot be used or the basement or the attic is avoided.

Straube et al. (2006a) found increased activation of the left (but not right) amygdala, left insula, left anterior cingulate, and left dorsomedial prefrontal cortex in fMRI scans in phobics exposed to aversive (spider) versus neutral (mushroom) images. In patients this phobic amygdala activation appears to be stronger and shorter than in nonphobics (Larson et al. 2006).

A greater response to fearful versus neutral faces of the right insular cortex compared to controls was described by (Wright et al. 2003). Amygdala hyperresponsivity was not observed. Straube et al. 2004a, b showed that phobia related words elicited activation in prefrontal cortex, insula, and posterior cingulate cortex.

In patients with specific phobias, SPECT could discover reduced tracer uptake in posterior brain regions under 
phobic stimulation (O'Carroll et al. 1993). In spider phobia Schienle et al. (2005) measured greater activation of the visual association cortex, amygdalae, right dorsolateral prefrontal cortex and right hippocampus. The supplementary motor area was activated, too.

Using $\left[{ }^{15} \mathrm{O}\right]-\mathrm{PET}$ in this patient group, a significant activation under phobic stimulation was measured in the amygdalae and thalamus (Wik et al. 1997). In a population of anxiety disorder patients of which only a part suffered from specific phobias PET could detect regional CBF differences with activation in the right frontal cortex, the right postero-medial orbitofrontal cortex, in both insulae and bilaterally in the nucleus lenticularis, and in the brainstem (Rauch et al. 1995). PET-stimulation with spiders versus butterflies in specific phobia revealed signal enhancement in the left fusiform gyrus and right parahippocampal gyrus. Habituation was seen in the anterior medial temporal lobe bilaterally. State anxiety correlated with left amygdala bilaterally, perirhinal cortex, right fusiform gyrus, and PAG, whereas phobic fear correlated with right hippocampal activity (Veltman et al. 2004).

In an article on pathologic emotions (Reiman 1997), associated brain regions to distinct functions on the base of PET-studies. According to this theory, the anterior temporal lobe is responsible for evaluation processes that attach exteroceptive sensoric information to an emotional component. The anterior insular areas combine potentially fearful cognitive and sensory information to negative emotion. Cingulum, vermis cerebelli, and midbrain regions become activated in both, normal and pathologic anxiety. The orbitofrontal cortex, the anterior insulae and the anterior cingulate appear to be of particular relevance, as they are possibly dysfunctional in all phobic disorders (Malizia et al. 1997). Treatment studies (Straube et al. 2006b), however, showed that in fMRI specific phobics had a reduction of previously hyperactivity of the insula and ACC after successful cognitive behavioural therapy. Goosens et al. (2007a) could demonstrate a reduction of elevated baseline amygdala activation after 2 weeks of exposure treatment to the feared stimuli and also a significant decline in the ACC and insular cortex. In a visual stimulation study, using fMRI, besides amygdala and pulvinar nucleus of the hypothalamus activation increase, ACC and left insula were stimulated more intensively in patients compared to controls (Goosens et al. 2007b). Schienle et al. (2007) reported decreased activation of the medial orbitofrontal cortex in a pre-treatment exposure that increased over the therapeutic process compared to a waiting list group, a finding also reported by Hermann et al. (2007) in patients exposed to phobia-relevant pictures compared to controls. Amygdala and insula activity was reduced with an experienced reduction of somatic anxiety over the course of cognitive behavioural treatment
(Schienle et al. 2007). A greater activity of these two structures linked to negative emotional responses was also reported by the meta-analysis by Etkin and Wager (2007). The bed nucleus of the stria terminalis as well as insula, ACC and thalamus had a higher BOLD response in anticipation of phobic versus neutral images in phobics compared to controls. ACC and anterior prefrontal cortex activity correlated with subjective anxiety in the patient group (Straube et al. 2007).

Results from specific phobia investigations underpin the theory of a hyperreactive amygdala more lateralized to the left hemisphere (although no differential investigations on conscious and unconscious perception of stimuli exist) diminishing with successful treatment. Anticipation of phobic stimulation activates the ACC and the insular cortex which may characterize state anxiety or the expectancy of adverse extero- and enteroception. Effects are decreasing with syndrome improvement. The medial prefrontal cortex appears to be hypoactive, although this has not been demonstrated consistently.

\section{Discussion}

A multitude of research has been targeting on possible brain regions involved in the origin of anxiety. Numerous studies suggest that the amygdala is critical for the acquisition and expression of fear. Conditioned fear in animals has been considered as a good model for human anxiety disorders, but animal models of anxiety have obvious limitations. Conditioned fear in animals can be directed to a specific stressor and is easily extinguished. Furthermore, animals have a limited or lacking ability to develop the capacity to worry excessively about the future. They do not completely parallel the complex cognitive processes that occur in anxious or even anxiety disorder ridden humans.

It can be assumed that human anxiety disorders are caused to a certain extent by differential activity in certain prefrontal cortex areas, the brain region that most separates us from animals. The human prefrontal cortex has not only been shown to be more developed than that of other mammals, but it also has unique morphology and gene expression. Neuroimaging studies consistently show abnormalities in the prefrontal cortex in anxiety disorder individuals. Thus, (Berkowitz et al. 2007) suggest that the very same cortical complexity that allows us to produce society and culture is also the origin of anxiety disorders.

Interestingly, preclinical and to a growing extent clinical studies have shown that the prefrontal cortex inhibits the amygdalae (the central nuclei). With the current knowledge we have, it can be assumed that the amygdalae are acutely activated when the individual is confronted to novel or generally fearful stimuli. Learned experience that a stressor 
can be coped with, is under control or is no longer worth paying attention to, is characterized by distinct regional prefrontal activation. This emotional processing can decrease amygdalae activation or, when a solution is lacking, leads to continuous limbic activation which is lateralizing the more to the non-dominant side the worse the stressor is perceived.

However, there appears to be a distinction between two classes of anxiety disorders. Those disorders involving intense fear and panic (panic disorder and specific phobias) seem to be characterized by a hypoactivity of distinct prefrontal cortex areas, thus desinhibiting the amygdalae. Disorders which involve worry and rumination such as generalized anxiety disorder or cognitions of negative consequences of social behaviour (SAD), on the other hand, seem to be characterized by a hyperactivity of the prefrontal cortex.

Studies of prefrontal cortical function in psychiatric illness should be a fruitful method for identifying effective treatment approaches. With improvements of methods a more sophisticated evaluation of different executive functions of the prefrontal cortex-and a differentiation of orbitofrontal, medial frontal including cingulate cortex, and dorsolateral prefrontal cortex functions will become increasingly inevitable - a more reliable picture of the neurocircuitry of anxiety disorders might emerge. In future investigations lateralization phenomena will have to be taken in account as important neurobiological features of anxiety disorders as shifts of activation to the non-dominant hemisphere with growing threat are commonly observed.

While previously mainly limbic structures were focussed on in anxiety, besides the prefrontal areas, distinct areas concerned with the perception of bodily states cannot be neglected. The insular cortices seem to be definitely involved in anxiety disorders contributing initiating and maintaining inputs modulating prefrontal and limbic structures in a way Damasio has described by the somatic marker hypothesis (Damasio 1996).

Neuroimaging studies on the effect of psychotherapy in patients suffering from diverse forms of psychopathology indicate that the mental functions and processes involved in diverse forms of psychotherapy exert a significant influence on brain activity (Beauregard 2007).

Beliefs and expectations can markedly modulate activity in brain regions involved in perception, movement, pain, and diverse aspects of emotion processing. Taken together, the findings of neuroimaging studies strongly support the view that the subjective nature and the intentional content of anxiety-related processes (e.g., thoughts, feelings, beliefs, volition) definitely modulates anxiety-network functioning and plasticity.

Despite an overlap of certain phenomena that cannot be ignored (unspecific alterations), anxiety in healthy subjects does not equal anxiety in anxiety disorders and the different disorders display distinct phenomena (besides expectable unspecific ones) characterizing their particular psychopathologic characteristics. Several controlled studies have pointed out that healthy subjects showed activation of brain region such as anxiety patients. However, phenomena are usually significantly more pronounced in patient groups.

Thus, anxiety syndromes involving a sensitized evaluation of environmental aspects, cognitive dysfunction (such as worries), spontaneous or situational panic detached from higher (prefrontal) cortical control instances, motivational aspects of avoidance combined with perception and appraisal of enteroceptive phenomena of discomfort create demarcable categories of disorders which become increasingly investigable with neuroimaging techniques.

Future perspectives concerning neuroimaging in anxiety disorders could become a useful tool in the control of treatment effects, for the staging of disorder severity and possibly for the identification of variables that predispose individuals to an expectable success or failure of a specific therapeutic approach. Neuroimaging techniques could support the diagnostic process of anxiety disorders and support the inevitable rationale of implying biological variables in the classification of anxiety disorders, characterizing specific endophenotypes.

Open Access This article is distributed under the terms of the Creative Commons Attribution Noncommercial License which permits any noncommercial use, distribution, and reproduction in any medium, provided the original author(s) and source are credited.

\section{References}

Agid O, Lerer B (1999) Risperidone augmentation of paroxetine in a case of severe, treatment-refractory obsessive-compulsive disorder without comorbid psychopathology. J Clin Psychiatry 60:5556

Amat J, Baratta MV, Paul E, Bland ST, Watkins LR, Maier SF (2005) Medial prefrontal cortex determines how stressor controllability affect behavior and dorsal raphe nucleus. Nat Neurosci 8:365371

Amir N, Klumpp H, Elias J, Bedwell AJ, Yanasak N, Miller LS (2005) Increasing activation of the anterior cingulate cortex during processing of disgust faces in individuals with social phobia. Biol Psychiatry 57:975-981

American Psychiatric Association (1998) Diagnostic and statistical manual for psychiatric disorders (DSM-IV) German Version. In: $\mathrm{Saß}$ H, Wittchen HU, Zaudig M (eds) Hogrefe, Göttingen

Arce E, Simmons AN, Lovero KL, Stein MB, Paulus MP (2008) Escitalopram effects on insula and amygdala BOLD activation during emotional processing. Psychopharmacology (Berl) 196:661-672

Ball S, Shekhar A (1997) Basilar artery response to hyperventilation in panic disorder. Am J Psychiatry 154:1603-1604

Benkelfat C, Bradwejn J, Meyer E, Ellenbogen M, Milot S, Gjedde A, Evans A (1995) Functional neuroanatomy of CCK4-induced anxiety in normal healthy volunteers. Am J Psychiatry 152:1180-1184 
Berkowitz RL, Coplan JD, Reddy DP, Gorman JM (2007) The human dimension: how the prefrontal cortex modulates the subcortical fear response. Rev Neurosci 18(3-4):191-207

Beauregard M (2007) Mind does really matter: evidence from neuroimaging studies of emotional self-regulation, psychotherapy, and placebo effect. Prog Neurobiol 81(4):218-236

Birbaumer N, Grodd W, Diedrich O, Klose U, Erb M, Lotze M, Schneider F, Weiss U, Flor H (1998) fMRI reveals amygdala activation to human faces in social phobics. Neuroreport 9:12231226

Bisaga A, Katz JL, Antonini A, Wright CE, Margouleff C, Gorman JM, Eidelberg D (1998) Cerebral glucose metabolism in women with panic disorder. Am J Psychiatry 155:1178-1183

Boshuisen ML, Ter Horst GJ, Paans AM, Reinders AA, den Boer JA (2002) rCBF differences between panic disorder patients and control subjects during anticipatory anxiety and rest. Biol Psychiatry 52:126-135

Brandt CA, Meller J, Keweloh L, Hoschel K, Staedt J, Munz D, Stoppe G (1998) Increased benzodiazepine receptor density in the prefrontal cortex in patients with panic disorder. J Neural Transm 105:1325-1333

Bremner JD (2004) Brain imaging in anxiety disorders. Expert Rev Neurother 4:275-284

Bremner JD, Innis RB, White T, Fujita M, Silbersweig D, Goddard AW, Staib L, Stern E, Cappiello A, Woods S, Baldwin R, Charney DS (2000) SPECT [I-123]iomazenil measurement of the benzodiazepine receptor in panic disorder. Biol Psychiatry 47:96-106

Buchsbaum MS, Wu JC, DeLisi LE, Holcomb HH, Hazlett E, Cooper-Langston K, Kessler R (1987) Positron emission tomography studies of basal ganglia and somatosensory cortex neuroleptic drug effects: differences between normal controls and schizophrenic patients. Biol Psychiatry 22:479-494

Bystritsky A, Pontillo D, Powers M, Sabb FW, Craske MG, Bookheimer SY (2001) Functional MRI changes during panic anticipation and imagery exposure. Neuroreport 12:3953-3957

Cameron OG, Huang GC, Nichols T, Koeppe RA, Minoshima S, Rose D, Frey KA (2007) Reduced gamma-aminobutyric acid(A)benzodiazepine binding sites in insular cortex of individuals with panic disorder. Arch Gen Psychiatry 64:793-800

Campbell DW, Sareen J, Paulus MP, Goldin PR, Stein MB, Reiss JP (2007) Time-varying amygdala response to emotional faces in generalized social phobia. Biol Psychiatry 62:455-463

Critchley HD, Mathias CJ, Dolan RJ (2002) Fear conditioning in humans: the influence of awareness and autonomic arousal on functional neuroanatomy. Neuron 33:653-663

Dager SR, Marro KI, Richards TL, Metzger GD (1994) Preliminary application of magnetic resonance spectroscopy to investigate lactate-induced panic. Am J Psychiatry 151:57-63

Dager SR, Richards T, Strauss W, Artru A (1997) Single-voxel 1HMRS investigation of brain metabolic changes during lactateinduced panic. Psychiatry Res 76:89-99

Dager SR, Friedman SD, Heide A, Layton ME, Richards T, Artru A, Strauss W, Hayes C, Posse S (1999) Two-dimensional proton echo-planar spectroscopic imaging of brain metabolic changes during lactate-induced panic. Arch Gen Psychiatry 56:70-77

Damasio AR (1996) The somatic marker hypothesis and the possible functions of the prefrontal cortex. Philos Trans R Soc Lond B Biol Sci 351:1413-1420

Dannlowski U, Ohrmann P, Bauer J, Kugel H, Arolt V, Heindel W, Kersting A, BAune BT, Suslow T (2007) Amygdala reactivity to masked negative faces is associated with automatic judgemental bias in major depression: a $3 \mathrm{~T}$ fMRI study. J Psychiatry Neurosci 32:423-429

Davidson JR, Krishnan KR, Charles HC, Boyko O, Potts NL, Ford SM, Patterson L (1993) Magnetic resonance spectroscopy in social phobia: preliminary findings. J Clin Psychiatry 54(Suppl):19-25

De Bellis MD, Keshavan MS, Shifflett H, Iyengar S, Dahl RE, Axelson DA, Birmaher B, Hall J, Moritz G, Ryan ND (2002) Superiortemporal gyrus volumes in pediatric generalized anxiety disorder. Biol Psychiatry 51:553-562

De Cristofaro MT, Sessarego A, Pupi A, Biondi F, Faravelli C (1993) Brain perfusion abnormalities in drug-naive, lactate-sensitive panic patients: a SPECT study. Biol Psychiatry 33:505-512

Domschke K, Braun M, Ohrmann P, Suslow T, Kugel H, Bauer J, Hohoff C, Kersting A, Engelien A, Arolt V, Heindel W, Deckert J (2006) Association of the functional-1019C/G 5-HT1A polymorphism with prefrontal cortex and amygdala activation measured with $3 \mathrm{~T}$ fMRI in panic disorder. Int J Neuropsychopharmacol 9:349-355

Drevets WC, Videen TQ, MacLeod AK, Haller JW, Raichle ME (1992) PET images of blood flow changes during anxiety: correction. Science 256:1696

Eren I, Tukel R, Polat A, Karaman R, Unal S (2003) Evaluation of regional cerebral blood flow changes in panic disorder with Tc99m-HMPAO SPECT. Psychiatry Res 123:135-143

Eser D, Leicht G, Lutz J, Wenninger S, Kirsch V, Schüle C, Karch S, Baghai T, Pogarell O, Born C, Rupprecht R, Mulert C (2007) Functional neuroanatomy of CCK-4-induced panic attacks in healthy volunteers. Hum Brain Mapp (E-pub)

Etkin A, Wager TD (2007) Functional neuroimaging of anxiety: a meta-analysis of emotional processing in PTSD, social anxiety disorder, and specific phobia. Am J Psychiatry 164:1476-1488

Etkin A, Klemenhagen KC, Dudman JT, Rogan MT, Hen R, Kandel ER, Hirsch J (2004) Individual differences intrait anxiety predict the response of the basolateral amygdala to unconsciously processed fearful faces. Neuron 44:1043-1055

Etkin A, Egner T, Peraza DM, Kandel ER, Hirsch J (2006) Resolving emotional conflict: a role for the rostral anterior cingulate cortex in modulating activity in the amygdala. Neuron 51:871-882

Evans KC, Wright CI, Wedig MM, Gold AL, Pollack MH, Rauch SL (2007) A functional MRI study of amygdala responses to angry schematic faces in social anxiety disorder. Depress Anxiety 10:1-10

Fontaine R, Breton G, Dery R, Fontaine S, Elie R (1990) Temporal lobe abnormalities in panic disorder: an MRI study. Biol Psychiatry 27:304-310

Fredrikson M, Wik G, Fischer H, Andersson J (1995) Affective and attentive neural networks in humans: a PET study of Pavlovian conditioning. Neuroreport 7:97-101

Furmark T, Fischer H, Wik G, Larsson M, Fredrikson M (1997) The amygdala and individual differences in human fear conditioning. Neuroreport 8:3957-3960

Furmark T, Tillfors M, Marteinsdottir I, Fischer H, Pissiota A, Langstrom B, Fredrikson M (2002) Common changes in cerebral blood flow in patients with social phobia treated with citalopram or cognitive-behavioral therapy. Arch Gen Psychiatry 59:425433

Furmark T, Tillfors M, Garpensrand H, Marteinsdottir I, Langström B, Oreland L, Fredrikson M (2004) Serotonin transporter polymorphism related to amygdala exitability and symptom severity in patients with social phobia. Neurosci Lett 362:189192

Furmark T, Appel L, Michelgard A, Wahlstedt K, Ahs F, Zancan S, Jacobsson E, Flyckt K, Grohp M, Bergström M, Pich EM, Nilsson LG, Bani M, Langström B, Fredrikson M (2005) Cerebral blood flow changes after treatment of social phobia with the neurokinin-1 antagonist GR205171, citalopram, or placebo. Biol Psychiatry 58:132-142

Garakani A, Bucjsbaum MS, Mewmark RE, Goodman C, Aaronson CJ, Martinez JM, Torosjan Y, Chu KW, Gorman JM (2007) The 
effect of doxapram on brain imaging with panic disorder. Eur Neuropsychopharmacol 17(10):672-686

Giardino ND, Friedman SD, Dager SR (2007) Anxiety, respiration, and cerebral blood flow: implications for functional brain imaging. Compr Psychiatry 48:103-112

Goddard AW, Mason GF, Almai A, Rothman DL, Behar KL, Petroff OA, Charney DS, Krystal JH (2001) Reductions in occipital cortex GABA levels in panic disorder detected with $1 \mathrm{~h}$ magnetic resonance spectroscopy. Arch Gen Psychiatry 58:556-561

Goddard AW, Mason GF, Appel M, Rothman DL, Gueorguieva R, Behar KL, Krystal JH (2004) Impaired GABA neuronal response to acute benzodiazepine administration in panic disorder. Am J Psychiatry 161:2186-2193

Goosens L, Schruers K, Peeters R, Griez E, Sunaert S (2007a) Visual presentation of phobic stimuli: amygdala activation via an extrageniculostriate pathway? Psychiatry Res 155:113-120

Goosens L, Sunaert S, Peeters R, Griez EJ, Schruers KR (2007b) Amygdala hyperfunction in phobic fear normalizes after exposure. Biol Psychiatry 62:1119-1125

Gorman JM, Kent JM, Sullivan GM, Coplan JD (2000) Neuroanatomical hypothesis of panic disorder, revised. Am J Psychiatry 157:493-505

Gottfried JA, Dolan RJ (2004) Human orbitofrontal cortex mediates extinction learning while accessing conditioned representations of value. Nature Neurosci 7:1144-1152

Grodd W, Schneider F, Klose U, Nagele T (1995) Functional magnetic resonance tomography of psychological functions exemplified by experimentally induced emotions. Radiologe 35:283-289

Haas BW, Omura K, Constable RT, Canli T (2007) Emotional conflict and neuroticism: personality-dependent activation in the amygdala and subgenual anterior cingulate. Behav Neurosci 121:249-256

Ham BJ, Sung Y, Kim N, Kim SJ, Kim JE, Kim DJ, Lee JY, Kim JH, Yoon SJ, Lyoo IK (2007) Decreased GABA levels in anterior cingulate and basal ganglia in medicated subjects with panic disorder: a proton magnetic resonance spectroscopy (1H-MRS) study. Prog Neuropsychopharmacol Biol Psychiatry 31:403-411

Hermann A, Schäfer A, Walter B, Stark R, Vaitl D, Schienle A (2007) Diminished medial prefrontal cortex activity in blood-injectioninjury phobia. Biol Psychiatry 75:124-130

Herry C, Bach DR, Esposito F, Di Salle F, Perrig WJ, Scheffler K, Luthi A, Seifritz E (2007) Processing of temporal unpredictability in human and animal amygdala. J Neurosci 27:5958-5966

Herwig U, Baumgartner T, Kaffenberger T, Bruhl A, Kottlow M, Schreiter-Gasser U, Abler B, Jancke L, Rufer M (2007) Modulation of anticipatory emotion and perception processing by cognitive control. Neuroimage 37:652-662

Jensen J, McIntosh AR, Crawley AP, Mikulis DJ, Remington G, Kapur S (2003) Direct activation of the ventral striatum in anticipation of aversive stimuli. Neuron 40:1251-1257

Kaschka W, Feistel H, Ebert D (1995) Reduced benzodiazepine receptor binding in panic disorders measured by iomazenil SPECT. J Psychiatr Res 29:427-434

Kelsey JE, Selvig AL, Knight BT (2000) Treatment of generalized anxiety disorder social phobia with the 5HT2 antagonist nefazodone, Anxiety disorders of America's 20th annual conference. Washington DC

Kilts CD, Kelsey JE, Knight B, Ely TD, DuBois Bowman F, Gross RE, Selvig A, Gordon A, Newport DJ, Nemeroff CB (2006) The neural correlates of social anxiety disorder and response to pharmacotherapy. Neuropsychopharmacology 31:2243-2253

Kuikka JT, Pitkanen A, Lepola U, Partanen K, Vainio P, Bergstrom KA, Wieler HJ, Kaiser KP, Mittelbach L, Koponen H (1995) Abnormal regional benzodiazepine receptor uptake in the prefrontal cortex in patients with panic disorder. Nucl Med Commun 16:273-280

LaBar KS, Gatenby JC, Gore JC, LeDoux JE, Phelps EA (1998) Human amygdala activation during conditioned fear acquisition and extinction: a mixed-trial fMRI study. Neuron 20:937-945

Lanzenberger RR, Mitterhauser M, Spindelegger C, Wadsak W, Klein N, Mien LK, Holik A, Attarbaschi T, Mossaheb N, Sacher J, Geiss-Granadia T, Kletter K, Kasper S, Tauscher J (2007) Reduced serotonin-1A receptor binding in social anxiety disorder. Biol Psychiatry 61(9):1081-1089

Larson CL, Schaefer HS, Siegle GJ, Jackson CAB, Anderle MJ, Davidson RJ (2006) Fear is fast in phobic individuals: amygdala activation in response to fear-relevant stimuli. Biol Psychiatry 60:410-417

Lauer CJ, Krieg JC (1992) Sleep electroencephalographic patterns and cranial computed tomography in anxiety disorders. Compr Psychiatry 33:213-219

LeDoux JE (1996) The emotional brain: the mysterious underpinnings of emotional life. Simon and Schuster, New York

Lee YS, Hwang J, Kim SJ, Sung YH, Kim J, Sim ME, Bae SC, Kim MJ, Lyoo IK (2006) Decreased blood flow of temporal regions of the brain in subjects with panic disorder. J Psychiatr Res 40:528534

Lepola U, Nousiainen U, Puranen M, Riekkinen P, Rimon R (1990) EEG and CT findings in patients with panic disorder. Biol Psychiatry 28:721-727

Li D, Chokka P, Tibbo P (2001) Toward an integrative understanding of social phobia. J Psychiatry Neurosci 26:190-202

Lorberbaum JP, Kose S, Johnson MR, Arana GW, Sullivan LK, Hamner MB, Ballenger JC, Lydiard RB, Brodrick PS, Bohning DE, George MS (2004) Neural correlates of speech anticipatory anxiety in generalized social phobia. Neuroreport 15:2701-2705

Maddock RJ, Buonocore MH, Kile SJ, Garrett AS (2003) Brain regions showing increased activation by threat-related words in panic disorder. Neuroreport 14:325-328

Malizia AL, Cunningham VJ, Bell CJ, Liddle PF, Jones T, Nutt DJ (1998) Decreased brain GABA(A)-benzodiazepine receptor binding in panic disorder: preliminary results from a quantitative PET study. Arch Gen Psychiatry 55:715-720

Malizia AL, Wilson SJ, Bell CM, Nutt DJ, Grasby PM (1997) Neural correlates of anxiety provocation in social phobia. Neuroimage 5:301-305

Maron E, Kuikka JT, Shlik J, Vasar V, Vanninen E, Tiihonen J (2004) Reduced brain serotonin transporter binding in patients with panic disorder. Psychiatry Res 132(2):173-181

Massana G, Gasto C, Junque C, Mercader JM, Gomez B, Massana J, Torres X, Salamero M (2002) Reduced levels of creatine in the right medial temporal lobe region of panic disorder patients detected with (1)H magnetic resonance spectroscopy. Neuroimage 16:836-842

Massana G, Serra-Grabulosa JM, Salgado-Pineda P, Gasto C, Junque C, Massana J, Mercader JM, Gomez B, Tobena A, Salamero M (2003a) Amygdalar atrophy in panic disorder patients detected by volumetric magnetic resonance imaging. Neuroimage 19(1):80-90

Massana G, Serra-Grabulosa JM, Salgado-Pineda P, Gasto C, Junque C, Massana J, Mercader JM (2003b) Parahippocampal gray matter density in panic disorder: a voxel-based morphometric study. Am J Psychiatry 160:566-568

Mathews AM, Wilson WH (1987) Cerebral blood flow changes. Psychiatry Res 23:285-294

Mathew SJ, Mao X, Coplan JD, Smnith EL, Sackeim HA, Gorman JM, Shungu DC (2004) Dorsolateral prefrontal cortical pathology in generalized anxiety disorder: a proton magnetic resonance spectroscopic imaging study. Am J Psychiatry 161(1):11191121 
McClure EB, Adler A, Monk CS, CAmeron J, Smith S, Nelson EE, Leibenluft E, Ernst M, Pine DS (2007) fMRI predictors of treatment outcome in pediatric anxiety disorders. Psychopharmacology (Berl) 191:97-105

Milad MR, Quirk GJ (2002) Neurons in medial prefrontal cortex signal memory for fear extinction. Nature 420:70-74

Miner CM, Davidson JR, Potts NL, Tupler LA, Charles HC, Krishnan KR (1995) Brain fluoxetine measurements using fluorine magnetic resonance spectroscopy in patients with social phobia. Biol Psychiatry 38:696-698

Monk CS, Nelson EE, McClure EB, Mogg K, Bradley BP, Leibenluft E, Blair RJ, Chen G, Charney DS, Ernst M, Pine DS (2006) Ventrolateral prefrontal cortex activation and attentional bias in response to angry faces in adolescents with generalized anxiety disorder. Am J Psychiatry 163:1091-1097

Monk CS, Telzer EH, Mogg K, Bradley BP, MAi X, Louro HM, Chen G, McClure-Tone EB, Ernst M, Pine DS (2008) Amygdala and ventrolateral prefrontal cortex activation to masked angry faces in children and adolescents with generalized anxiety disorder. Arch Gen Psychiatry 65:568-576

Morris JS, Frith CD, Perrett DI, Rowland D, Young AW, Calder AJ, Dolan RJ (1996) A differential neural response in the human amygdala to fearful and happy facial expressions. Nature 383:812-815

Neumeister A, Bain E, Nugent AC, Carson RE, Bonne O, Luckenbaugh DA, Eckelman W, Herscovitch P, Charney DS, Drevets WC (2004) Reduced serotonin type 1A receptor binding in panic disorder. J Neurosci 24:589-591

Norbury R, Mackay CE, Cowen PJ, Goodwin GM, Harmer CJ (2007) Short-term antidepressant treatment and facial processing. A functional magnetic resonance imaging study. Br J Psychiatry 190:531-532

Nordahl TE, Semple WE, Gross M, Mellman TA, Stein MB, Goyer P, King AC, Uhde TW, Cohen RM (1990) Cerebral glucose metabolic differences in patients with panic disorder. Neuropsychopharmacology 3:261-272

Nutt DJ (2001) Neurobiological mechanisms in generalized anxiety disorder. J Clin Psychiatry 62(Suppl 11):22-27 discussion 28

O'Carroll RE, Moffoot AP, Van Beck M, Dougall N, Murray C, Ebmeier KP, Goodwin GM (1993) The effect of anxiety induction on the regional uptake of $99 \mathrm{mTc}$-exametazime in simple phobia as shown by single photon emission tomography (SPET). J Affect Disord 28:203-210

Ontiveros A, Fontaine R, Breton G, Elie R, Fontaine S, Dery R (1989) Correlation of severity of panic disorder and neuroanatomical changes on magnetic resonance imaging. J Neuropsychiatry Clin Neurosci 1:404-408

Paulus MP, Feinstein JS, Simmons A, Stein MB (2004) Anterior cingulate activation in high trait anxious subjects is related to altered error processing during decision making. Biol Psychiatry 55:1179-1187

Pfleiderer B, Zinkirciran S, Arolt V, Heindel W, Deckert J, Domschke K (2007) fMRI amygdala activation during a spontaneous panic attack in apatient with panic disorder. World J Biol Psychiatry 8(4):269-272

Phan KL, Wager T, Taylor SF, Liberzon I (2002) Functional neuroanatomy of emotion: a meta-analysis of emotion activation studies in PET and fMRI. Neuroimage 16:331-348

Phan KL, Fitzgerald DA, Nathan PJ, Tancer ME (2006) Association between amygdala hyperactivity to harsh faces and severity of social anxiety in generalized social phobia. Biol Psychiatry 59:424-429

Phelps EA, Delgado MR, Nearing KI, LeDoux JE (2004) Extinction learning in humans: role of the amygdala and the vmPFC. Neuron 43:897-903
Pillay SS, Gruber SA, Rogowska J, Simpson N, Yurgelun-Todd DA (2006) fMRI of fearful facial affect recognition in panic disorder: the cingulate gyrus-amygdala connection. J Affect Disord 94:173-181

Pillay SS, Rogowska J, Gruber SA, Simpson N, Yurgelun-Todd DA (2007) Recognition of happy facial affect in panic disorder: an fMRI study. J Anxiety Disord 21:381-393

Potts NL, Book S, Davidson JR (1996) The neurobiology of social phobia. Int Clin Psychopharmacol 11(Suppl 3):43-48

Prasko J, Horacek J, Zalesky R, Kopecek M, Novak T, PAskova B, Skrdlantova L, Belohlavek O, Höschl C (2004) The change of regional brain metabolism (18FDG PET) in panic disorder during the treatment with cognitive behavioral treatment or antidepressants. Neuro Endocrinol Lett 25(5):348-348

Protopopescu X, Pan H, Tuescher O, Cloitre M, Goldstein M, Engelien A, Yang Y, Gorman J, LeDoux J, Stern E, Silbersweig D (2006) Increased brainstem volume in panic disorder: a voxelbased morphometric study. Neuroreport 17:361-363

Quirk GJ, Kikhtik E, Pelletier J, Paré D (2003) Stimulation of medial prefrontal cortex decreases the responsiveness of central amygdala output neurons. J Neurosci 23(25):8800-8807

Rauch SL, Savage CR, Alpert NM, Miguel EC, Baer L, Breiter HC, Fischman AJ, Manzo PA, Moretti C, Jenike MA (1995) A positron emission tomographic study of simple phobic symptom provocation. Arch Gen Psychiatry 52:20-28

Reiman EM (1997) The application of positron emission tomography to the study of normal and pathologic emotions. J Clin Psychiatry 58(16):4-12

Reiman EM, Fusselman MJ, Fox PT, Raichle ME (1989) Neuroanatomical correlates of anticipatory anxiety [published erratum appears in Science 1992 Jun 19;256(5064)1696]. Science 243:1071-1074

Sakai Y, Kumano H, Nishikawa M, Sakano Y, Kaiya H, Imabayashi E, Ohnishi T, Matsuda H, Yasuda A, Sato A, Diksic M, Kuboki $\mathrm{T}$ (2005) Cerebral glucose metabolism associated with a fear network in panic disorder. Neuroreport 16(9):927-931

Sareen J, Campbell DW, Leslie WD, Malisza KL, Stein MB, Paulus MP, Kravetsky LB, Kjernisted KD, Walker JR, Reiss JP (2007) Striatal function in generalized social phobia: a functional magnetic resonance imaging study. Biol Psychiatry 61:396-404

Schienle A, Schäfer A, Walter B, Stark R, Vaitl D (2005) Brain activation of spider phobics towards disorder-relevant, generally disgust- and fear-inducuíng pictures. Neurosci Lett 388:1-6

Schienle A, Schäfer A, Hermann A, Rohrmann S, Vaitl D (2007) Symptom provocation and reduction in patients suffering from spider phobia: an fMRI study on exposure therapy. Eur Arch Psychiatry Clin Neurosci 257:486-493

Schlegel S, Steinert H, Bockisch A, Hahn K, Schloesser R, Benkert O (1994) Decreased benzodiazepine receptor binding in panic disorder measured by IOMAZENIL-SPECT. A preliminary report. Eur Arch Psychiatry Clin Neurosci 244:49-51

Schneider F, Weiss U, Kessler C, Muller-Gartner HW, Posse S, Salloum JB, Grodd W, Himmelmann F, Gaebel W, Birbaumer N (1999) Subcortical correlates of differential classical conditioning of aversive emotional reactions in social phobia. Biol Psychiatry 45:863-871

Schneier FR, Liebowitz MR, Abi-Dargham A, Zea-Ponce Y, Lin SH, Laruelle M (2000) Low dopamine $\mathrm{D}(2)$ receptor binding potential in social phobia. Am J Psychiatry 157:457-459

Schunck T, Erb G, Mathis A, Gilles C, Namer IJ, Hode Y, Demaziere A, Luthringer R, Macher JP (2006) Functional magnetic resonance imaging characterization of CCK-4-induced panic attack and subsequent anticipatory anxiety. Neuroimage 31:1197-1208 
Schwartz CE, Wright CI, Shin LM, Kagan J, Rauch SL (2003) Inhibited and uninhibited infants "grown up": adult amygdalar response to novelty. Science 300:1952-1953

Shioiri T, Kato T, Murashita J, Hamakawa H, Inubushi T, Takahashi S (1996) High-energy phosphate metabolism in the frontal lobes of patients with panic disorder detected by phase-encoded 31PMRS. Biol Psychiatry 40:785-793

Simmons A, Matthews SC, Stein MB, Paulus MP (2004) Anticipation of emotionally aversive visual stimuli activates right insula. Neuroreport 15:2261-2265

Somerville LH, Kim H, Johnstone T, Alexander AL, Whalen PJ (2004) Human amygdala responses during presentation of happy and neutral faces: correlations with state anxiety. Biol Psychiatry 55:897-903

Stein MB, Leslie WD (1996) A brain single photon-emission computed tomography (SPECT) study of generalized social phobia. Biol Psychiatry 39:825-828

Stein MB, Goldin PR, Sareen J, Zorrilla LT, Brown GG (2002) Increased amygdala activation to angry and contemptuous faces in generalized social phobia. Arch Gen Psychiatry 59:1027-1034

Stein MB, Simmons AN, Feinstein JS, Pauls MP (2007) Increased amygdala and insula activation during emotion processing in anxiety-prone subjects. Am J Psychiatry 164:318-327

Stewart RS, Devous MD Sr, Rush AJ, Lane L, Bonte FJ (1988) Cerebral blood flow changes during sodium-lactate-induced panic attacks. Am J Psychiatry 145:442-449

Straube T, Mentzel HJ, Glauer M, Miltner WHR (2004a) Brain activation to phobia related words in phobic subjects. Neurosci Lett 372:204-208

Straube T, Kolassa IT, Glauer M, Mentzel HJ, Miltner WHR (2004b) Effect of task conditions on brain responses to threatening faces in social phobics: an event related functional magnetic resonance imaging study. Biol Psychiatry 56:921-930

Straube T, Mentzel HJ, Miltner WHR (2005) Common and distinct brain activation to threat and safety signals in social phobia. Neuropsychobiology 52:163-168

Straube T, Mentzel HJ, Miltner WHR (2006a) Neural mechanisms of automatic and direct processing of phobogenic stimuli in specific phobia. Biol Psychiatry 59:162-170

Straube T, Glauer M, Dilger S, Mentzel HJ, Miltner WHR (2006b) Effects of cognitive behavioral therapy on brain activation in specific phobia. Neuroimage 29:125-135

Straube T, Mentzel HJ, Miltner WH (2007) Waiting for spiders: brain activation during anticipatory anxiety in spider phobics. Neuroimage 37:1427-1436

Tiihonen J, Kuikka J, Bergstrom K, Lepola U, Koponen H, Leinonen E (1997) Dopamine reuptake site densities in patients with social phobia. Am J Psychiatry 154:239-242

Tillfors M, Furmark T, Marteinsdottir I, Fredrikson M (2002) Cerebral blood flow during anticipation of public speaking in social phobia: a PET study. Biol Psychiatry 52:1113-1119

Tupler LA, Davidson JR, Smith RD, Lazeyras F, Charles HC, Krishnan KR (1997) A repeat proton magnetic resonance spectroscopy study in social phobia. Biol Psychiatry 42:419-424

Uchida RR, Del-Ben CM, Santos AC, Araujo D, Crippa JA, Guimaraes FS, Graeff FG (2003) Decreased left temporal lobe volume of panic patients measured by magnetic resonance imaging. Braz J Med Biol Res 36:925-929

Uhde TW, Berrettini WH, Roy Byrne PP, Boulenger JP, Post RM (1987) Platelet $[3 \mathrm{H}]$ imipramine binding in patients with panic disorder. Biol Psychiatry 22:52-58

van Ameringen M, Mancini C, Oakman JM, Kamath M, Nahmias C, Szechtman HA (1998) Pilot study of PET in social phobia. Biol Psychiatry 43:31-37 van den Heuvel OA, Veltman DJ, Groenewegen HJ, Witter MP, Merkelbach J, Cath DC, van Balkom AJ, van Oppen P, van Dyck R (2005) Disorder-specific neuroanatomical correlates of attentional bias in obsessive-compulsive disorder, panic disorder, and hypochondriasis. Arch Gen Psychiatry 62:922-933

van der Linden GJ, Stein DJ, van Balkom AJ (2000) The efficacy of the selective serotonin reuptake inhibitors for social anxiety disorder (social phobia) a meta-analysis of randomized controlled trials. Int Clin Psychopharmacol 15(Suppl 2):S15-S23

Veit R, Flor H, Erb M, Hermann C, Lotze M, Grodd W, Birbaumer N (2002) Brain circuits involved in emotional learning in antisocial behavior and social phobia in humans. Neurosci Lett 328:233236

Veltman DJ, Tuinebreijer WE, Winkelman D, Lamertsma AA, Witter MP, Dolan RJ, Emmelkamp PMG (2004) Neurophysiological correlates of habituation during exposure in spider phobia. Psychiatry Res 132:149-158

Volpe U, Merlotti E, Mucci A, Galderisi S (2004) The contribution of brain imaging to the study of panic disorder. Epidemiol Psichiatr Soc 13(4):237-248

Vythilingam M, Anderson ER, Goddard A, Woods SW, Staib LH, Charney DS, Bremner JD (2000) Temporal lobe volume in panic disorder. A quantitative magnetic resonance imaging study. Psychiatry Res 99:75-82

Whalen PJ, Johnstone T, Somerville LH, Nitschke JB, Polis S, Alexander AL, Davidson RJ, Kalin NH (2008) A functional magnetic resonance imaging predictor of treatment response to venlafaxine in generalized anxiety disorder. Biol Psychiatry 63:858-863

World Health Organisation (WHO) 1993 International classification of psychiatric disorders (Internationale Klassifikation psychischer Störungen): ICD-10, Kapitel V(F); klinisch-diagnostische Leitlinien, 2.Auflage; WHO, Bern, Göttingen, Toronto, Seattle

Wik G, Fredrikson M, Fischer H (1997) Evidence of altered cerebral blood-flow relationships in acute phobia. Int J Neurosci 91:253263

Woods SW, Koster K, Krystal JK, Smith EO, Zubal IG, Hoffer PB, Charney DS (1988) Yohimbine alters regional cerebral blood flow in panic disorder (letter). Lancet 2:678

Wright CI, Martis B, McMullin K, Shin LM, Rauch SL (2003) Amygdala and insular responses to emotionally valenced human faces in small animal specific phobia. Biol Psychiatry 54:10671076

Wu J, Buchsbaum M, Hershey T, Hazlett E, Sciotte N, Johnson J (1991) PET in generalized anxiety disorder. Biol Psychiat 29:1181-1199

Wurthmann C, Bogerts B, Gregor J, Baumann B, Effenberger O, Dohring W (1997) Frontal CSF enlargement in panic disorder: a qualitative CT-scan study. Psychiatry Res 76:83-87

Yaguez L, Coen S, Gregory LJ, Amaro E, Altman C, Brammer M, Bullmore ET, Williams SCR, Aziz Q (2005) Brain response to visceral aversive conditioning: a functional magnetic resonance imaging study. Gastroenterology 128:1819-1829

Yoo HK, Kim MJ, Kim SJ, Sung YH, Sim ME, Lee YS, Song SY, Kee BS, Lyoo IK (2005) Putaminal gray matter volume decrease in panic disorder: an optimized voxel-based morphometry study. Eur J Neurosci 22:2089-2094

Yoon KL, Fitzgerald DA, Angstadt M, McCarron RA, Phan KL (2007) Amygdala reactivity to emotional faces at high and low intensity in generalized social phobia: a 4-Tesla functional MRI study. Psychiatry Res 154:93-98 